\title{
Molecular Differentiation and Detection of Ginseng-Adapted Isolates of the Root Rot Fungus Cylindrocarpon destructans
}

\author{
K. A. Seifert, C. R. McMullen, D. Yee, R. D. Reeleder, and K. F. Dobinson
}

First and third authors: Eastern Cereal and Oilseed Research Centre, Agriculture and Agri-Food Canada, 960 Carling Ave., Ottawa, Ontario N5V 4T3, Canada; second, fourth, and fifth authors: Southern Crop Protection and Food Research Centre, Agriculture and Agri-Food Canada, 1391 Sandford St., London, Ontario N5V 4T3, Canada; second and fifth authors: Department of Microbiology and Immunology, The University of Western Ontario, London, Ontario, Canada; and fifth author: Department of Biology, The University of Western Ontario, London, Ontario, Canada.

Accepted for publication 7 July 2003.

\begin{abstract}
Seifert, K. A., McMullen, C. R., Yee, D., Reeleder, R. D., and Dobinson, K. F. 2003. Molecular differentiation and detection of ginseng-adapted isolates of the root rot fungus Cylindrocarpon destructans. Phytopathology 93:1533-1542.

The soilborne fungus Cylindrocarpon destructans (teleomorph: Neonectria radicicola) causes root rot in a wide range of plant hosts; the disease is of particular concern in ginseng production, and in conifer and fruit tree nurseries. $\beta$-Tubulin gene and rRNA gene internal transcribed spacer (ITS) sequence data and pathogenicity assays were used to characterize isolates of $C$. destructans from ginseng and other hosts. The results of these studies demonstrated a high amount of sequence divergence among strains identified as $C$. destructans or $N$. radicicola, suggesting the existence of several phylogenetic species in this complex.

to species status. Certain highly aggressive ginseng isolates from Ontario, Korea, and Japan have identical ITS and $\beta$-tubulin sequences, and form a monophyletic clade (designated "clade a"); these strains are identified as $C$. destructans $\mathrm{f}$. sp. panacis. Other ginseng strains clustered in monophyletic groups with strains from angiosperm and conifers. A subtractive hybridization method was used to isolate genomic DNA sequences with diagnostic potential from the aggressive $C$. destructans Ontario ginseng isolate 1640. One of these sequences was similar to the rRNA gene intergenic spacer from a Fusarium oxysporum isolate from Pinus ponderosa, and hybridized to DNA from $F$. oxysporum and all $C$. destructans isolates tested. Primers were designed that could be used to amplify this sequence specifically from the highly aggressive, ginsengadapted $C$. destructans isolates from Ontario and Korea and other members of clade a.
\end{abstract} Accordingly, we propose that the two varieties of $N$. radicicola be raised
North American ginseng (Panax quinquefolius L.) is an economically important cash crop in several regions of North America (23). Dried roots of this species are shipped to Asia, where they are used in both traditional Asian medicine and in the manufacture of various foods. The production of harvestable ginseng roots requires a 3- to 4-year cultivation period and, throughout this time, ginseng is susceptible to diseases caused by both foliar and soilborne root-infecting fungi; yield losses to disease can reach as high as $30 \%$ (E. Littley, personal communication). One of the major pathogens of ginseng is Cylindrocarpon destructans (teleomorph: Neonectria radicicola) $(16,27)$; cylindrocarpon root rot, of both mature ginseng plants and seedlings, has long been implicated in replant failure $(13,25)$. This species is a common soilborne fungus with a wide geographic distribution and, in common with other root-pathogenic fungi such as Fusarium oxysporum and $F$. solani, includes both parasitic and apparently saprophytic strains $(3,28)$. Pathogenic strains of $C$. destructans are a concern not only in ginseng production, but also in the propagation of conifer and fruit tree nursery stocks $(12,32)$.

$C$. destructans is closely related to a number of well-known pathogenic species in the family Nectriaceae (Hypocreales), including other species of Cylindrocarpon, the mycotoxin-producing genus Fusarium (with teleomorphs in Gibberella, Haematonectria, Albonectria, and Cosmospora), and Cylindrocladium

Corresponding author: K. F. Dobinson; E-mail address: dobinsonk@agr.gc.ca

Publication no. P-2003-0925-02R

For the Department of Agriculture and Agri-Food, Government of Canada. (C) Minister of Public Works and Government Services Canada 2003. (teleomorphs in Calonectria) (26). Mantiri et al. (16) estimated that there are approximately 125 described species of Cylindrocarpon. Samuels and Brayford (27) revised the taxonomy of the $N$. radicicola complex and its anamorphs, based on morphological and cultural studies. They recognized three varieties within Nectria radicicola (sic), namely var. radicicola (anamorph $C$. destructans var. destructans), var. coprosmae (anamorph $C$. destructans var. coprosmae), and var. macroconidialis (anamorph $C$. macroconidialis). Mantiri et al. (16) transferred many of the Nectria spp. with Cylindrocarpon anamorphs, including Nectria radicicola, to Neonectria Wollenw., in accordance with the new classification of the order Hypocreales proposed by Rossman et al. (26).

Although the classification of $C$. destructans within Cylindrocarpon (anamorphic Nectriaceae, Hypocreales) is well established, little is known about the genetic variation within this morphologically defined species. Because genetically distinct populations may differ in important phenotypic characters, including survival in the field, host range, aggressiveness, and even susceptibility to different disease control treatments, a better understanding of the genetic and pathogenic variation with the species would benefit the development of appropriate disease-management strategies. Thus, the first objective of the current study was to assess genetic and pathogenic variation within $C$. destructans, particularly among strains isolated from ginseng. The results of an amplified fragment length polymorphism (AFLP) analysis (19) suggested substantial genetic variation among isolates from various hosts and geographic origins, and a very high degree of similarity, which strongly suggested clonality, between Korean ginseng isolates and all but two Ontario ginseng isolates. Based on these data, representative ginseng isolates (from Ontario, Nova Scotia, and Asia) and iso- 
lates from other hosts were selected for pathogenicity tests, and a broader range of isolates was selected for analysis of rRNA gene internal transcribed spacer (ITS) and $\beta$-tubulin gene sequences. The results of these analyses are presented here.

The second objective of the study was to test and develop DNA-based methods for the detection of $C$. destructans on ginseng. The standard methods of diagnosis are both time-consuming and laborious, requiring isolation of the fungus from diseased tissue. Moreover, because the fungus grows slowly, colonies arising from diseased tissue often are overgrown by more rapidly growing fungi (25). The inability to efficiently monitor $C$. destructans in soil and in plant tissue has hampered the development and implementation of effective disease management practices; rapid and reliable methods to detect the pathogen in the soil would be useful for monitoring the efficacy of fungicides, fumigants, soil amendments, and other cropping practices to control cylindrocarpon root rot of ginseng. A sensitive method to detect $C$. destructans on seed also would be valuable in assessing the quality of seed, which often is contaminated with C. destructans (25), and the efficacy of seed sanitation methods.

Putative species-specific primers have been developed for polymerase chain reaction (PCR)-based detection of several species of Cylindrocarpon or Neonectria. Brown et al. (5) developed an assay for $N$. galligena (sic), a causal agent of Nectria canker on several tree species, using a unique primer ChInt, designed from partial ITS1 sequences, in combination with the universal primer ITS4 (33). Langrell (14) found that this primer set lacked specificity when tested against some closely related species, and used complete ITS sequences from a broader range of strains to design a more specific primer pair. A nested PCR-based assay was developed for the detection of $C$. destructans in pine and spruce seedlings (12). In the present study, we assessed the utility of the latter assay to detect isolates of $C$. destructans from a variety of nonconifer hosts, including ginseng, and further developed a PCRbased method for the detection of a specific subgroup of aggressive ginseng isolates.

\section{MATERIALS AND METHODS}

Fungal isolates. Cylindrocarpon isolates used in this study are from ginseng grown in Japan, commercial ginseng gardens in Canada (Ontario, Nova Scotia, Alberta, and British Columbia), and Korea, and from other hosts, including conifers and fruit trees (Table 1). Monospore cultures were generated as required, using previously described methods (9). In order to determine the phylogenetic relationships between these anamorph-derived strains of C. destructans and known teleomorphs, representative strains of the three described varieties of Nectria radicicola also were included in the study (Table 1). Isolates of F. oxysporum, F. solani, Botrytis cinerea, Colletotrichum coccodes, Phytophthora sojae, Rhizopus arrhizus, Sclerotinia sclerotiorum, Trichoderma viridae, and Ulocladium atrum are from the culture collections of $\mathrm{K}$. Dobinson and R. Reeleder.

For long-term storage, Cylindrocarpon cultures were grown across sterile cellulose filter disks, and the filters were air dried and stored at $-20^{\circ} \mathrm{C}$ over desiccant. Representative cultures have been deposited in the Canadian Collection of Fungal Cultures (CCFC) at the Eastern Cereal and Oilseed Research Centre (ECORC), Ottawa, Ontario, Canada.

Virulence and host range assays. Based on the reported host range of Cylindrocarpon destructans (3) and on cultivation in ginseng-growing regions of particular crop species, the following plant varieties were used for pathogenicity and host range tests: North American ginseng (Panax quinquefolius), barley (Hordeum vulgare line 953111-101, University of Guelph), muskmelon ( $\mathrm{Cu}$ cumis melo cv. Earliqueen 190E), alfalfa (Medicago sativa, University of Guelph), kidney bean (Phaseolus vulgaris cv. California Red), pea (Pisum sativum cv. Improved Laxton's Progress
UT230), apple (Malus pumila cv. Empire), oats (Avena sativa cv. OAC Paisley), Kentucky bluegrass (Poa pratensis), cucumber (Cucumis sativus cv. Straight 8), corn (Zea mays cv. Seneca Horizon), soybean (Glycine max cv. KG62), tomato (Lycopersicon esculentum cv. 360 Beefmaster VFN), parsnip (Pastinaca sativa cv. UT244 Harris), cyclamen (Cyclamen indicum cv. 847B Salmon Sierra Hybrid), and white spruce (Picea glauca).

Inoculum of Cylindrocarpon destructans was prepared from cultures grown in V8 broth $(15 \mathrm{ml}$ of broth per 100-mm glass petri dish) at room temperature $\left(22^{\circ} \mathrm{C}\right)$, for 2 to 3 weeks. Mycelial mats were blended in a cell homogenizer, and the macerate was filtered through two layers of sterile cheesecloth to separate hyphae from conidia. Conidia were collected from the filtrate by centrifugation, suspended in sterile deionized water at a concentration of $1 \times$ $10^{7}$ conidia $\mathrm{ml}^{-1}$, and stored at $8^{\circ} \mathrm{C}$ until required (for up to $4 \mathrm{~h}$ ).

Ginseng seedlings were grown from stratified seed. Stratification was done by storing recently harvested seed at $6 \pm 2{ }^{\circ} \mathrm{C}$ for 2 months, then at $-1 \pm 1^{\circ} \mathrm{C}$ for 6 months. The seed then was warmed to $15 \pm 1^{\circ} \mathrm{C}$ for 6 months, stored for an additional 4 to 5 months at $-1 \pm 1^{\circ} \mathrm{C}$, and finally transferred to $8 \pm 2{ }^{\circ} \mathrm{C}$ until radicles emerged. Seeds with elongating radicles were transplanted into cell trays (S601; Kord Products Ltd., Bramalea, Ontario, Canada) filled with Pro Mix BX (Premier Horticulture, Inc., Rivière-du-Loup, Quebec, Canada) or Professional Seedling and Plug Mix (Micro-Mix; ASB-Greenworld, Mt. Elgin, Ontario, Canada), and grown for 1 to 2 months in a greenhouse at 20 to $24^{\circ} \mathrm{C}$ under polycloth shade.

Prior to inoculation, ginseng seedlings were transplanted into potting mix in sodium hypochlorite-disinfested 10 -cm-diameter pots. A 1-cm layer of autoclaved vermiculite was placed in the bottom of the pot, followed by a 3- to 4-cm layer of potting mix dampened with sterilized water. A depression was made in the mix and eight seedlings were placed in the depression. A 20-ml aliquot of the spore suspension was pipetted evenly over the roots of the seedlings. Sufficient potting mix was added to cover the tops of the roots while leaving $2 \mathrm{~cm}$ of the pot unfilled. The potting medium then was watered with sterile water, and a 1-cm layer of autoclaved vermiculite was added to the surface. Liquid 20-20-20 (N-P-K) fertilizer $(10 \mathrm{ml})$ was added to each pot. The seedlings were placed in a growth chamber at $20^{\circ} \mathrm{C}, 95 \%$ humidity, under a 12-h photoperiod $\left(44 \mu \mathrm{mol} \mathrm{s}{ }^{-1} \mathrm{~m}^{-2}\right.$ ). A randomized complete block design was used, with one replicate pot per treatment in each block. Two trials were carried out, with four replicate pots per treatment in each trial.

Visual symptoms of disease stress (wilting, damping-off, and plant death) were recorded every other day from the start of the experiment. The trials were terminated after 4 weeks. Final stand counts (FSCs) were determined for each replicate pot. After washing roots free of potting medium, the plants were assessed for disease severity using a 1-to- 8 scale, where $1=$ symptomless roots and $8=$ dead plant. For each treatment, disease severity values of individual plants in a replicate pot were averaged, to provide a value for each of the four replicate pots. Samples of diseased root tissue were surface disinfested and plated onto MRBA medium (25) to assess presence of the fungus in the roots.

Data were analyzed using the SAS GLM procedure for analysis of variance (SAS Institute Inc., Cary, NC), with treatment mean separations carried out using Tukey's Studentized Range test. A preliminary analysis of the data showed no significant trial-treatment interactions $(P=0.2032 ; F=1.66)$; therefore, the data from the two trials were combined. For the merged data set $(n=8)$, a disease severity index (DI) (34) was calculated for each treatment replicate, based on the root rot severity value of each plant. The proportion of stand loss in each replicate was determined and arcsine transformation was used to normalize data (15).

For host range assays, seedlings were grown in cell trays (one plant per cell) containing potting mix. Because of different rates of growth for each species, seedlings varied in age from 14 days 
to 6 months at the time of inoculation. For each plant species and isolate of $C$. destructans tested, four replicates (six seedlings per replicate) were inoculated, and four were not inoculated. As an additional positive control, ginseng seedlings were similarly prepared and inoculated. Inoculum $\left(10 \mathrm{ml}\right.$ at $1 \times 10^{7}$ conidia $\left.\mathrm{ml}^{-1}\right)$ was added to the surface of the potting medium at the base of the stem. Plants were watered as needed. After 4 weeks, plants were removed and examined for root disease using the root disease severity scale described above. For selected plants from each species-isolate combination, the presence of the fungus in the roots was assessed as described previously.

Isolation of fungal DNA. Genomic DNA was isolated from fungal cultures using two methods. For the first method, cultures were grown for 14 days on malt extract agar under fluorescent and near UV light, or in Fusarium broth (20) for 3 to 5 days at room temperature on a rotary shaker $(150 \mathrm{rpm})$. Mycelia were scraped

TABLE 1. Cylindrocarpon and Neonectria isolates used in this study

\begin{tabular}{|c|c|c|c|c|c|}
\hline Species & Isolate $^{\mathrm{W}}$ & Host & Geographic origin ${ }^{x}$ & $\begin{array}{c}\text { Year } \\
\text { isolated }\end{array}$ & Source $^{z}$ \\
\hline C. destructans & 265 (CCFC 221059) & $\begin{array}{l}\text { North American ginseng } \\
\text { (Panax quinquefolius) }\end{array}$ & Canada, ON & 1989 & R. D. Reeleder \\
\hline C. destructans & 842 & P. quinquefolius & $\mathrm{ON}$ & 1991 & R. D. Reeleder \\
\hline C. destructans & 999 & P. quinquefolius & $\mathrm{ON}$ & 1992 & R. D. Reeleder \\
\hline C. destructans & 1287 & P. quinquefolius & $\mathrm{ON}$ & 1994 & R. D. Reeleder \\
\hline \multirow[t]{2}{*}{ C. destructans } & 1557 (CBS 308.35; & & & & \\
\hline & CCFC 226729) & P. quinquefolius & ON & 1930 & R. D. Reeleder \\
\hline C. destructans & 1561 & P. quinquefolius & $\mathrm{ON}$ & 1996 & R. D. Reeleder \\
\hline C. destructans & 1567 & P. quinquefolius & ON & 1996 & R. D. Reeleder \\
\hline C. destructans & 1570 (CCFC 226727) & P. quinquefolius & $\mathrm{ON}$ & 1996 & R. D. Reeleder \\
\hline C. destructans & 1596 & P. quinquefolius & $\mathrm{ON}$ & 1996 & R. D. Reeleder \\
\hline C. destructans & 1598 & P. quinquefolius & $\mathrm{ON}$ & 1996 & R. D. Reeleder \\
\hline C. destructans & 1634 (CCFC 226728) & P. quinquefolius & $\mathrm{ON}$ & 1997 & R. D. Reeleder \\
\hline C. destructans & 1635 & P. quinquefolius & $\mathrm{ON}$ & 1997 & R. D. Reeleder \\
\hline C. destructans & 1636 & P. quinquefolius & $\mathrm{ON}$ & 1997 & R. D. Reeleder \\
\hline C. destructans & 1637 & P. quinquefolius & $\mathrm{ON}$ & 1997 & R. D. Reeleder \\
\hline C. destructans & 1639 & P. quinquefolius & $\mathrm{ON}$ & 1997 & R. D. Reeleder \\
\hline C. destructans & 1640 & P. quinquefolius & $\mathrm{ON}$ & 1997 & R. D. Reeleder \\
\hline C. destructans & 1641 & P. quinquefolius & $\mathrm{ON}$ & 1997 & R. D. Reeleder \\
\hline C. destructans & 1642 & P. quinquefolius & ON & 1997 & R. D. Reeleder \\
\hline C. destructans & 1666 & P. quinquefolius & Canada, NS & 1998 & R. D. Reeleder \\
\hline C. destructans & CDC-N-9A & P. quinquefolius & Canada, AB & 1998 & K. F. Chang \\
\hline C. destructans & NSAC-SH-1 & P. quinquefolius & NS & 1998 & S. Hong \\
\hline C. destructans & NSAC-SH-2 & P. quinquefolius & NS & 1998 & S. Hong \\
\hline C. destructans & NSAC-SH-2.5 & P. quinquefolius & NS & 1998 & S. Hong \\
\hline C. destructans & 2000-M-15 & P. quinquefolius & $\mathrm{BC}$ & 1999 & M. Walker \\
\hline C. destructans & CY9207 & Asian ginseng $(P$. ginseng $)$ & $\begin{array}{l}\text { Korea, } \\
\text { Jeungpyung }\end{array}$ & 1992 & Y.-H. Yu \\
\hline C. destructans & CY9801 & $P$. ginseng & Korea, Suwon & 1998 & Y.-H. Yu \\
\hline C. destructans & CY9802 & $P$. ginseng & Suwon & 1998 & Y.-H. Yu \\
\hline C. destructans f. sp. panacis & IFO 31881 & P. ginseng & Japan & 1969 & IFO \\
\hline C. destructans f. sp. panacis & IFO 31882 & $P$. ginseng & Japan & 1969 & IFO \\
\hline C. destructans & CR20 & Douglas fir (Pseudotsuga menziesii) & Canada, BC & 1998 & P. Axelrood \\
\hline C. destructans & CR26 & P. menziesii & $\mathrm{BC}$ & 1998 & P. Axelrood \\
\hline C. destructans & CR29 & P. menziesii & $\mathrm{BC}$ & 1998 & P. Axelrood \\
\hline C. destructans & CR36 (CCFC 226721) & P. menziesii & $\mathrm{BC}$ & 1998 & P. Axelrood \\
\hline C. destructans & JAT1378 & Flowering dogwood (Cornus floridae) & $\mathrm{ON}$ & 1987 & J. A. Traquair \\
\hline C. destructans & JAT1397 & Pear (Pyrus communis) & $\mathrm{ON}$ & 1983 & J. A. Traquair \\
\hline C. destructans & JAT1590 (CCFC 185721) & Apricot (Prunus armeniaca) & $\mathrm{ON}$ & 1987 & J. A. Traquair \\
\hline C. destructans & JAT1591 (CCFC 185722) & P. armeniaca & $\mathrm{ON}$ & 1987 & J. A. Traquair \\
\hline C. destructans & CCFC 150670 & Kentucky bluegrass (Poa pratensis) & $\mathrm{AB}$ & $1974(\mathrm{~A})$ & CCFC \\
\hline C. destructans & CCFC 144524 & Grape (Vitis vinifera) & $\mathrm{ON}$ & 1972 & CCFC \\
\hline C. destructans & CCFC 139398 & Sour cherry (Prunus cerasus) & $\mathrm{ON}$ & $1971(\mathrm{~A})$ & $\mathrm{CCFC}$ \\
\hline C. destructans & $94-1628$ & White spruce (Picea glauca) & Canada, QC & 1994 & R. C. Hamelin \\
\hline C. destructans & 94-1685 (CCFC 226730) & P. glauca & QC & 1994 & R. C. Hamelin \\
\hline Cylindrocarpon sp. & JAT1401 & P. communis & ON & 1983 & J. A. Traquair \\
\hline Cylindrocarpon sp. & $94-1356$ & Black spruce (P. mariana) & QC & 1994 & R. C. Hamelin \\
\hline Cylindrocarpon sp. & 94-2057 (CCFC 226735) & P. mariana & QC & 1994 & R. C. Hamelin \\
\hline C. cylindroides & CR6 (CCFC 226722) & P. menziesii & $\mathrm{BC}$ & $\mathrm{n} / \mathrm{a}$ & P. Axelrood \\
\hline C. cylindroides & CR21 & P. menziesii & $\mathrm{BC}$ & $\mathrm{n} / \mathrm{a}$ & P. Axelrood \\
\hline C. didymum & JAT 1366 (CCFC 182772) & Prunus sp. & $\mathrm{ON}$ & 1982 & J. A. Traquair \\
\hline C. didymum & CCFC 185212 & Pyrus sp. & ON & 1982 & $\mathrm{CCFC}$ \\
\hline N. radicicola & IMI 313237 & Arecoid palm & Indonesia & 1985 & G. J. Samuels \\
\hline N. coprosmae & GJS 85-39 & Metrosideros sp. & New Zealand & 1985 & G. J. Samuels \\
\hline N. galligena & KAS1224 & Apple (Malus sylvestris) & $\mathrm{BC}$ & 1999 & P. Haag \\
\hline N. macroconidialis & GJS 83-162 & Astelia $\mathrm{sp}$ & New Zealand & 1983 & G. J. Samuels \\
\hline
\end{tabular}

${ }^{w}$ Alternative isolate designations are in parentheses.

${ }^{x}$ AB, Alberta; BC, British Columbia; NS, Nova Scotia; ON, Ontario; QC, Quebec.

y Date followed by (A) indicates accession year; n/a indicates information not available.

${ }^{2}$ K. F. Chang, Alberta Agriculture, Brooks, AB; S. Hong, Nova Scotia Agricultural College, Truro, NS; M. Walker, Agriculture and Agri-Food Canada, Pacific Agriculture Research Centre (PARC), Summerland, BC; Y.-H. Yu, Korea Ginseng and Tobacco Research Institute, Daejon, Korea; IFO, Institute for Fermentation (now National Institute of Technology and Evaluation, Kazusakamatari), Osaka, Japan; P. Axelrood, B.C. Research Inc., Vancouver, BC; J. A. Traquair, Agriculture and Agri-Food Canada, SCPFRC, London, ON; Canadian Collection of Fungal Cultures, Agriculture and Agri-Food Canada, Ottawa, ON; R. C. Hamelin, Canadian Forest Service, Sainte-Foy, QC; G. J. Samuels, SBML, USDA-ARS, Beltsville, MD; and P. Haag, PARC. 
from the colonies, or harvested from the liquid cultures by filtration through cheesecloth, and DNA was extracted by a modified version of the DNA isolation procedure of Edwards et al. (10), with subsequent digestion of RNA using RNase A. Alternatively, stationary cultures were grown in 30 to $35 \mathrm{ml}$ of liquid complete medium $(\mathrm{CM})(2,7)$ at $24^{\circ} \mathrm{C}$ with a 12 -h light cycle for 5 to 7 days, and mycelia were harvested by vacuum filtration through Whatman No. 1 filter paper (Whatman Ltd., Maidstone, England), quick frozen in liquid nitrogen, and ground into a fine powder using a mortar and pestle. DNA was isolated from the powdered mycelia using a hexadecyltrimethylammonium bromide extraction method as described previously (8).

Isolation by subtractive hybridization of $C$. destructans-specific sequences from ginseng isolate 1640. Suppression-PCR subtractive hybridization was done essentially according to protocols from the Clontech PCR-Select Bacterial Genomic Subtraction Kit User Manual, Diatchenko et al. (6), and Akopyants et al. (1), using AluI-digested genomic DNA from C. destructans ginseng isolate 1640, and $C$. didymium strain CCFC 185212 as the tester and driver DNAs, respectively. Hybridization and amplification reactions were done in a GeneAmp PCR System 9700 Thermocycler (Perkin-Elmer Applied Biosystems, Norwalk, CT). Subtraction products were cloned into the pGEM-T Easy vector (Promega Corp., Madison, WI). Plasmids from randomly selected recombinant clones were purified from bacterial cultures by an alkaline lysis method using the QIAprep 8 Miniprep Kit according to manufacturer's protocols (Qiagen Inc., Mississauga, Ontario, Canada). Sequence analysis of cloned subtraction products (19), was done at the Southern Crop Protection and Food Research Centre (SCPFRC) of Agriculture and Agri-Food Canada, London, Ontario, Canada.

PCR amplification. Unless otherwise noted, all reagents were from Life Technologies (Mississauga, Ontario, Canada). For $\beta$ tubulin gene amplification, different protocols were used in the ECORC and SCPFRC laboratories. Amplification reactions done in Ottawa were performed on a Thermolyne Temp-Tronic Thermocycler (Dubuque, IA). Reactions $(20 \mu \mathrm{l})$ contained 20 to $100 \mathrm{ng}$ of fungal DNA, $1 \times$ PCR buffer $(20 \mathrm{mM}$ Tris- $\mathrm{HCl}, \mathrm{pH} 8.4,50 \mathrm{mM}$ $\mathrm{KCl}), 200 \mu \mathrm{M}$ each dNTP, $1.5 \mathrm{mM} \mathrm{MgCl}_{2}, 0.5 \mu \mathrm{M}$ each primers T10 and T222 (21), and 0.5 units of Native Taq DNA Polymerase (Perkin-Elmer Applied Biosystems). The reaction profile included an initial denaturation for $3 \mathrm{~min}$ at $94^{\circ} \mathrm{C}$, followed by 30 cycles of $1 \mathrm{~min}$ of denaturation at $94^{\circ} \mathrm{C}, 1.5 \mathrm{~min}$ of annealing at 56 to $65^{\circ} \mathrm{C}$, $2 \mathrm{~min}$ of extension at $72^{\circ} \mathrm{C}$, with a final extension of $10 \mathrm{~min}$ at $72^{\circ} \mathrm{C}$.

$\beta$-Tubulin gene amplification reactions done at SCPFRC, and all other amplifications described below, were carried out in GeneAmp PCR System 9600 or 9700 Thermocyclers, and con- tained $1 \times$ PCR buffer, $2.5 \mathrm{mM} \mathrm{MgCl} 2,200 \mu \mathrm{M}$ each dNTP, and 20 to $30 \mathrm{ng}$ of template DNA in a final volume of $50 \mu \mathrm{l}$. For amplification of $\beta$-tubulin gene sequences, reactions included $0.24 \mu \mathrm{M}$ each primers T11 (21) and T222, and $1 \mathrm{U}$ of Platinum Taq DNA polymerase (Invitrogen Canada Inc., Burlington, Ontario, Canada). Amplification conditions were as follows: 3 min of denaturation at $94^{\circ} \mathrm{C}$, followed by 35 cycles of $45 \mathrm{~s}$ of denaturation at $94^{\circ} \mathrm{C}, 45 \mathrm{~s}$ of annealing at $64^{\circ} \mathrm{C}, 60 \mathrm{~s}$ of extension at $72^{\circ} \mathrm{C}$, and a final extension of $7 \mathrm{~min}$ at $72^{\circ} \mathrm{C}$.

ITS sequences were amplified for sequence analysis using primers ITS4 (33) and ITS1F (11). Reaction conditions were as described above, except that 30 amplification cycles were used and the annealing temperature was $55^{\circ} \mathrm{C}$. For amplification of ITS sequences with the Dest1/Dest4 primer set (12), reactions and conditions were as described for the ITS4/ITS1F primer set, except that reactions included 0.2 units of Platinum Taq Polymerase and $0.12 \mu \mathrm{M}$ each primer, and the annealing temperature was $58^{\circ} \mathrm{C}$.

PrimerSelect 4.03 (DNAStar Inc., Madison, WI) was used to design PCR primers (CdU3 5'-GACGATTCGGGCCGTATCTGTG-3' and CdL1b 5'-CAGCGGCGCCCACTAACAAC-3') complementary to a putative intergenic spacer (IGS) sequence (GenBank Accession No. AY037554) isolated from C. destructans by subtractive hybridization (described previously). The sequence was amplified as described for the ITS sequence, except that the annealing temperature was $66^{\circ} \mathrm{C}$.

DNA sequencing and sequence data analyses. $\beta$-Tubulin gene sequences amplified with primers T10 and T222 were purified using the freeze-squeeze method (31), or with the GeneClean II Kit (Bio/Can Scientific Inc., Mississauga, Ontario, Canada), and sequenced with the Open Gene Automated DNA Sequencing System (Visible Genetics Inc., Toronto) following the manufacturer's directions. The cycle sequencing reaction followed the protocol for the ThermoSequenase cycle sequencing core kit (Amersham Pharmacia Biotech, Montreal), with the following reagents in each $25-\mu$ reaction: 20 to $50 \mathrm{ng}$ of purified template, $1 \times$ sequencing reaction buffer $1,3.5 \mu \mathrm{l}$ of dimethyl sulfoxide, $5 \mathrm{mM}$ each CY5 dye-labeled primer (T10 or reverse T224) (21), and 10 units of ThermoSequenase (Amersham Biosciences, Inc., Baie d'Urfé, Quebec, Canada). The cycle sequencing reaction profile included an initial denaturation for $5 \mathrm{~min}$ at $94^{\circ} \mathrm{C}$, followed by 30 cycles of $30 \mathrm{~s}$ of denaturation at $94^{\circ} \mathrm{C}, 45 \mathrm{~s}$ of annealing at 56 or $60^{\circ} \mathrm{C}$, $1 \mathrm{~min}$ of extension at $72^{\circ} \mathrm{C}$, with a final extension of $10 \mathrm{~min}$ at $72^{\circ} \mathrm{C}$. Samples were denatured at $85^{\circ} \mathrm{C}$ for $2 \mathrm{~min}$, quenched on ice, and loaded onto acrylamide gels prepared using MicroCel Cassettes and SureFill cartridges from Visible Genetics, Inc. Automated runs were performed using the MicroGene Blaster following the manufacturer's directions.

TABLE 2. Virulence of selected Cylindrocarpon destructans isolates on ginseng (Panax quinquefolius) seedlings

\begin{tabular}{|c|c|c|c|c|c|c|}
\hline \multirow[b]{2}{*}{ Isolate $^{\mathrm{x}}$} & \multirow[b]{2}{*}{ Geographic origin ${ }^{y}$} & \multirow[b]{2}{*}{ Host } & \multirow[b]{2}{*}{ Clade $^{z}$} & \multicolumn{3}{|c|}{ Disease ratings ${ }^{\mathrm{w}}$} \\
\hline & & & & DI & FSC & Percent loss \\
\hline CY9207 & Korea & P. ginseng & $\mathrm{a}$ & $7.3 \mathrm{a}$ & $2.8 \mathrm{~b}$ & $56.2 \mathrm{a}$ \\
\hline 1561 & $\mathrm{ON}$ & P. quinquefolius & $\mathrm{a}$ & $7.2 \mathrm{a}$ & $4.2 \mathrm{~b}$ & $53.1 \mathrm{ab}$ \\
\hline CY9801 & Korea & P. ginseng & a & $7.0 \mathrm{a}$ & $4.5 \mathrm{~b}$ & 29.7 b \\
\hline NSAC-SH-1 & NS & P. quinquefolius & $\mathrm{c}$ & $2.5 \mathrm{~b}$ & $8.0 \mathrm{a}$ & $0 \mathrm{c}$ \\
\hline NSAC-SH-2 & NS & P. quinquefolius & $\mathrm{c}$ & $2.4 \mathrm{bc}$ & $8.0 \mathrm{a}$ & $0 \mathrm{c}$ \\
\hline $94-1628$ & QC & Picea glauca & $\mathrm{f}$ & $2.0 \mathrm{bc}$ & $8.0 \mathrm{a}$ & $0 \mathrm{c}$ \\
\hline 94-2057 & QC & Picea mariana & n.a. & $1.3 \mathrm{c}$ & $8.0 \mathrm{a}$ & $0 \mathrm{c}$ \\
\hline Control & $\ldots$ & $\ldots$ & $\ldots$ & $1.3 \mathrm{c}$ & $7.8 \mathrm{a}$ & $0 \mathrm{c}$ \\
\hline CV & $\ldots$ & $\ldots$ & $\ldots$ & 16.45 & 16.41 & 63.1 \\
\hline
\end{tabular}

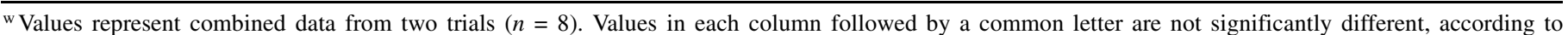
Tukey's Studentized Range test $(\alpha=0.01)$. Sterile distilled water was used for control inoculations. Disease was assessed using the following ratings: DI $($ mean disease index $)=[\Sigma(N 1 \times 1)+(N 2 \times 2)+\ldots(N t \times t)] /(N 1+N 2+\ldots N t)$, where $N 1=$ number of plants with disease rating of 1 , and so on, and $t=8$ (maximum disease rating); FSC $=$ mean final stand count; Percent loss $=$ mean percent decline in stand during the trial.

x All isolates except 94-2057 are C. destructans; CV, coefficient of variance for combined data set.

y ON, Ontario; NS, Nova Scotia; QC, Quebec.

${ }^{\mathrm{z}}$ Clade designations are according to Figures 2 and 3; isolates not assigned to a clade are indicated by n.a. 
The $\beta$-tubulin gene products amplified with the T11 and T222 primers, and rRNA gene ITS amplicons were purified using the QIAquick PCR Purification Kit (Qiagen), according to the supplier's recommendations. Primers used for amplification were also used for sequencing. Amplification products were sequenced using the BigDye Terminator Cycle Sequencing system and the ABI PRISM 377 DNA Sequencer (Applied Biosystems, Foster, CA) at SCPFRC.

For phylogenetic analyses, the majority of sequences were aligned using the Clustal algorithm in MegaAlign (DNAStar Inc.) or the pileup option of the Wisconsin Package (version 10.1; Genetics Computer Group, Madison, WI), and corrected by visual inspection. Several sequences were inserted into the alignments manually. Alignments were analyzed using heuristic searches with default options using PAUP *4.0b4a (30). Separate analyses were run for the complete $\beta$-tubulin data set (46 strains), complete ITS data set (35 sequences derived in this study and 18 sequences from GenBank), and a combined analysis of reduced $\beta$-tubulin and ITS data sets ( 25 of the 29 strains for which we had sequences for each gene). In order to determine whether the $\beta$-tubulin and ITS sequence data could be combined, the Partition Homogeneity Test as implemented in PAUP was run with 1,000 replicates. To assess the statistical reliability of the analyses, 1,000 replicates of a fast step-wise addition bootstrap and jackknife analyses were run using heuristic searches. C. cylindroides CCFC 226722, C. didymum CCFC 185212, and isolate JAT1591 (CCFC 185722) were used as outgroups in all analyses except for the complete ITS data set, where Nectria cinnabarina AF163025 was used as the outgroup.

\section{RESULTS}

Variation in virulence and host range among isolates of $\boldsymbol{C}$. destructans. Several ginseng and conifer isolates of $C$. destructans were selected for assessment of their aggressiveness to ginseng. The Ontario ginseng isolate 1561 and Korean ginseng isolates CY9207 and CY9801 consistently caused severe root rot of seedlings (Table 2). In a subsequent analysis, Ontario ginseng isolate 1640 was found to be as aggressive as isolate 1561 (data not shown). In most cases, roots were almost completely destroyed (Fig. 1A) and surviving plants, although upright, had little or no healthy root tissue remaining. In contrast, other isolates from ginseng (NSAC-SH-1 and NSAC-SH-2) caused only slight damage to roots, as did spruce isolates 94-1628 and 94-2057, which for the most part was not significantly different from that observed in the uninoculated controls (Table 2; Fig. 1B and C). All isolates could be recovered from inoculated ginseng plants (data not shown).

The host range of ginseng isolates NSAC-SH-1, CY9801, and 1561 was tested on 15 different host species, including ginseng. Few symptoms were observed on any of the other plant species tested, with the exception of pea (data not shown). C. destructans was not recovered from uninoculated control plants, or inoculated oats and blue grass, and only infrequently recovered from other plant-isolate combinations. The levels of virulence observed on ginseng were consistent in these assays and similar to those presented in Table 2 and, based on these results, the assay procedures were assumed to be suitable for the expression of virulence on the other host species. However, we note the possibility that virulence could have been expressed on these species under different environmental conditions. Similarly, the sporadic recovery of isolates in some tests likely reflects saprophytic growth on dead root tissue, but suggests that further host range testing of these isolates is merited.

Molecular variation among $\boldsymbol{C}$. destructans isolates. ITS sequence data were generated for 35 strains of Cylindrocarpon and Neonectria spp., and aligned with 18 sequences obtained from GenBank, with Nectria cinnabarina AF163025 used as an out- group. Included in this analysis were two Japanese strains of $C$. destructans f. sp. panacis (IFO 31881 and IFO 31882), previously shown to cause a severe root rot of ginseng (18); it was, therefore, of some interest to determine the phylogenetic relationship of these historical isolates to those from Ontario and Korea, which also cause severe disease. Heuristic searches of this data set resulted in $>10,000$ equally parsimonious trees. In order to complete the analysis without filling the computer's memory, we limited the number of saved trees to 5,000. The results of heuristic analysis, with consensus and bootstrap and jackknife support incorporated, are shown in Figure 2; the topology of the tree received weak bootstrap and jackknife support but is relatively well supported by the consensus analysis. The structure recognizes clades I (with diverse species, including the type of Cylindrocarpon, $C$. cylindroides, and the apple pathogen $N$. galligena), and III (the $N$. radicicola complex), as delimited by Mantiri et al. (16) using mitochondrial small subunit rRNA gene sequences.
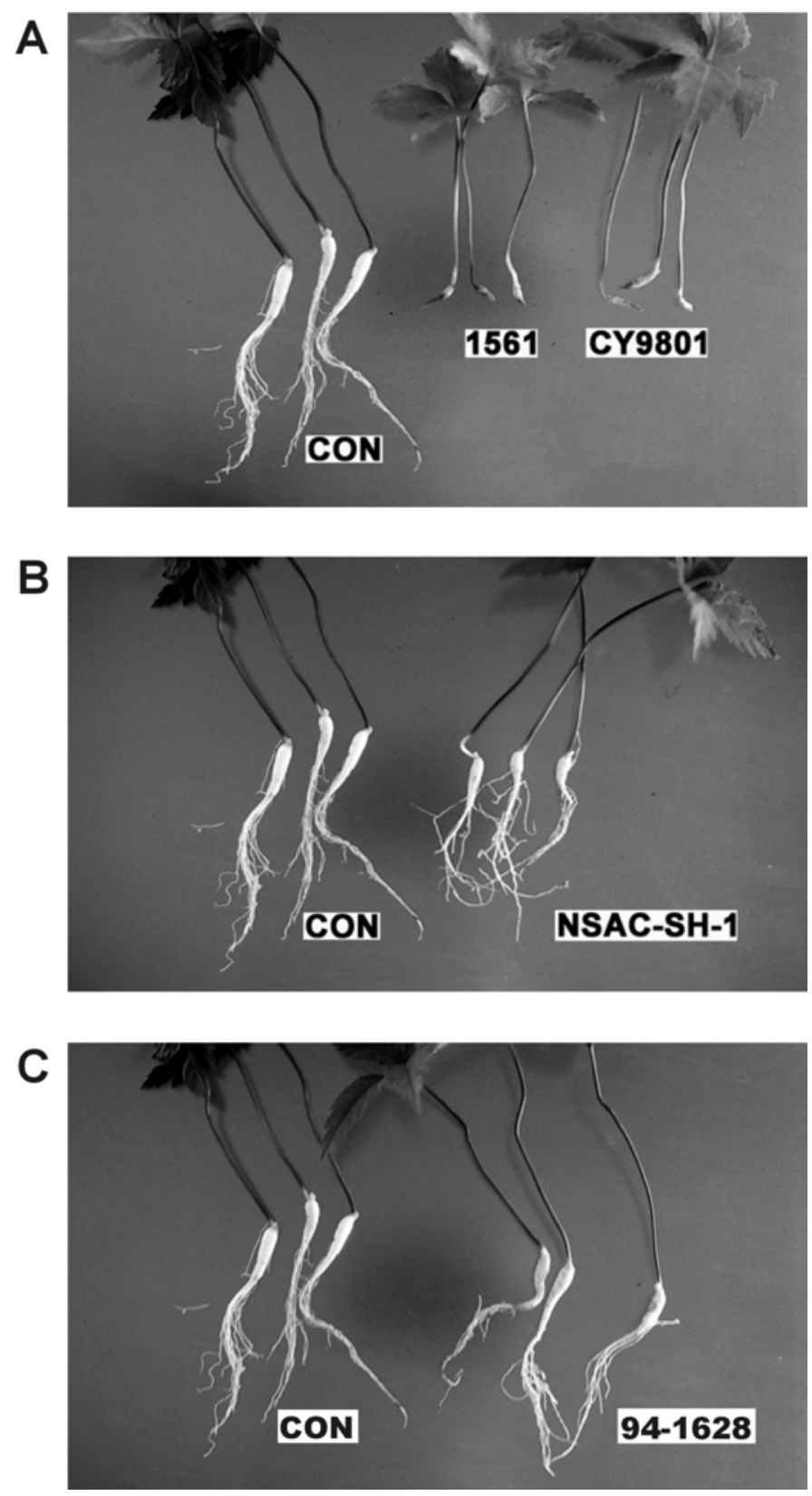

Fig. 1. Ginseng seedlings infected with highly or weakly aggressive ginseng isolates of Cylindrocarpon destructans. Seedlings were inoculated as described with A, ginseng isolates 1561 (Ontario) or CY9801 (Korea), B, Nova Scotia ginseng isolate NSAC-SH-1, or C, Quebec spruce isolate 94-1628. Controls (CON) were inoculated with sterile distilled water. 
It is unclear if clade II of Mantiri et al. (16) is represented in this data set; it may be represented by either the three sequences at the base of the tree, or the clade projecting from the base of clade I, which includes $N$. coccinea var. coccinea and var. fagi, and $N$. punicea.

Within the $N$. radicicola complex, most strains from Panax, including those Ontario and Asian strains demonstrated to cause a severe root rot on ginseng (see above and 18), formed a large clade (marked "a") with a few isolates from other hosts. Two Panax-derived strains were found in a separate clade (marked "b"). There is remarkable ITS divergence within the $N$. radicicola complex, even among sequences derived from strains originating with ascospores (designated as Neonectria in the tree). The occurrence of identical ITS sequences among different species in clade I is a dramatic contrast to the wide variation among strains identified as the same species in clade III.

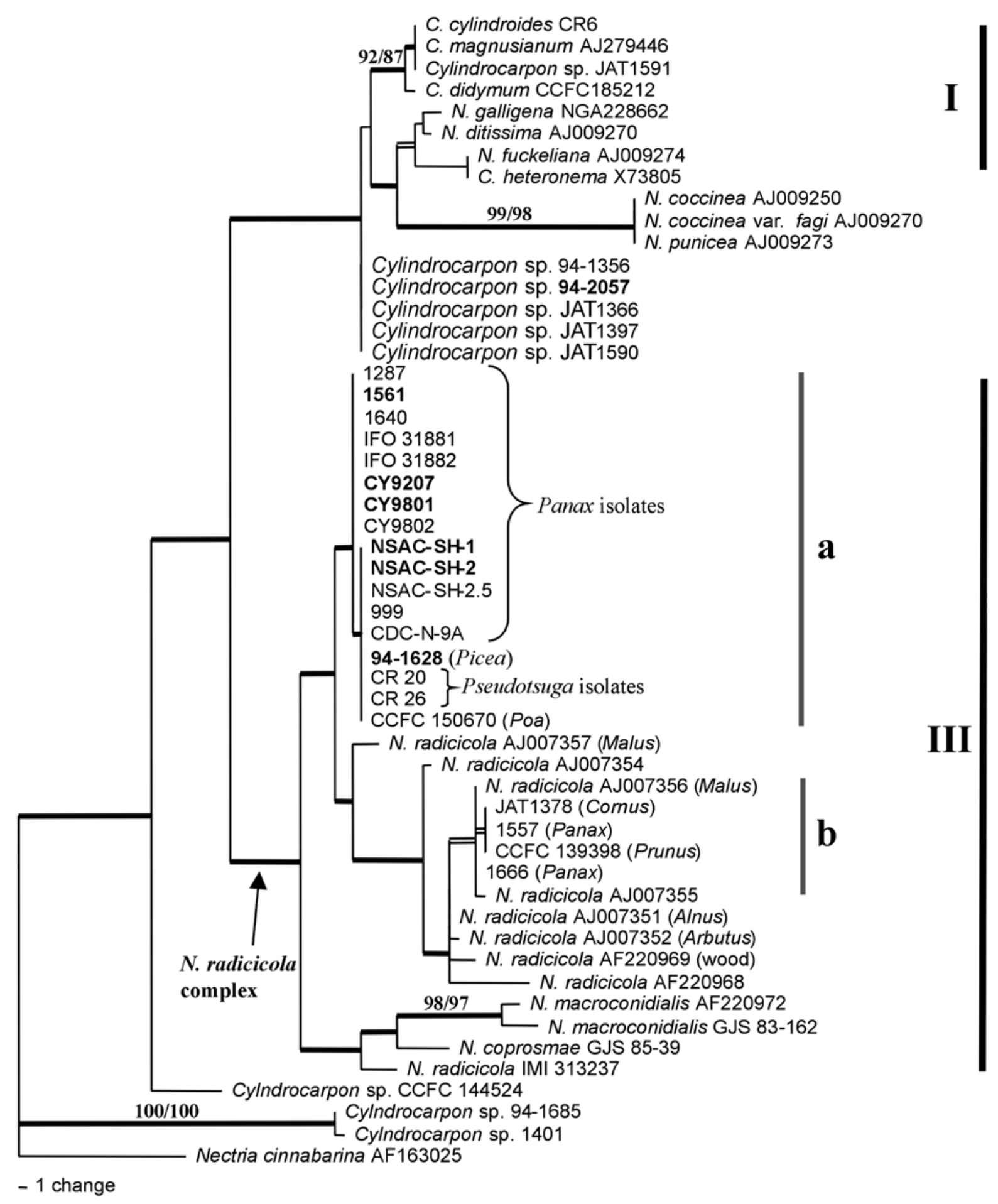

Fig. 2. Phylogenetic analysis of rRNA gene internal transcribed spacer (ITS) sequence data, including 35 sequences derived in this study (GenBank Accession Nos. AY295301 to AY295335), and 18 sequences from GenBank. Of 5,000 most parsimonious trees (MPTs) from an incomplete search constrained with the results of a preliminary bootstrap analysis, 1 is shown (122 characters, 241 steps, CI 0.693 , RI 0.891 , RC 0.693 , HI 0.307 ). Branches occurring in $100 \%$ of the MPTs (strict consensus) are indicated in bold type; those in $90 \%$ or more of the trees have double lines. The numbers above certain branches are bootstrap and jackknife values above 70\%. Isolates used in pathogenicity tests are in bold type. The Roman numerals and vertical lines designate the major clades within Cylindrocarpon recognized by Mantiri et al. (16), based on mitochondrial small subunit rRNA gene sequences. 
$\beta$-Tubulin sequence data were generated for 37 strains of the $N$. radicicola complex, aligned with nine sequences from related species and subjected to heuristic searches using PAUP. One of the most parsimonious trees is shown in Figure 3. The main clades of this tree are well supported by bootstrap and jackknife analyses. The majority of contemporary ginseng strains from Ontario formed a well-supported monophyletic clade (marked "a") with identical sequences separated from the nearest neighbors by six unique base changes. Also included in this clade were the Asian ginseng strains found in clade a of the ITS tree. Three isolates from Ontario, Nova Scotia, and British Columbia ginseng, and one from Ontario sour cherry, formed a well-supported second clade (marked "b"). A third clade (marked "c") includes three recent strains isolated from Panax spp. from Nova Scotia, but is not well supported with bootstrap or jackknife analyses. Conifer- derived strains were dispersed among three distinct monophyletic groups, all of which included strains from other kinds of hosts (clades d, e, and f). The Cylindrocarpon isolates from black spruce, and two strains from pear and apricot, previously identified as $C$. destructans (32), formed a weakly supported clade (marked "g") at the base of the tree, that was sister to the outgroup and quite genetically distant from the Nectria radicicola complex.

The partition homogeneity test (PHT) rejected the combination of the ITS and $\beta$-tubulin data sets when the 29 strains in common were included $(P=0.009)$. The problem was traced to the sequences for $N$. radicicola IMI 313237, $N$. coprosmae GJS-39, and $N$. macroconidialis GJS 83-162; when these three sets of sequences were removed, the PHT accepted combination of the data $(P=0.84)$. Separate PHTs with any one of these sequence

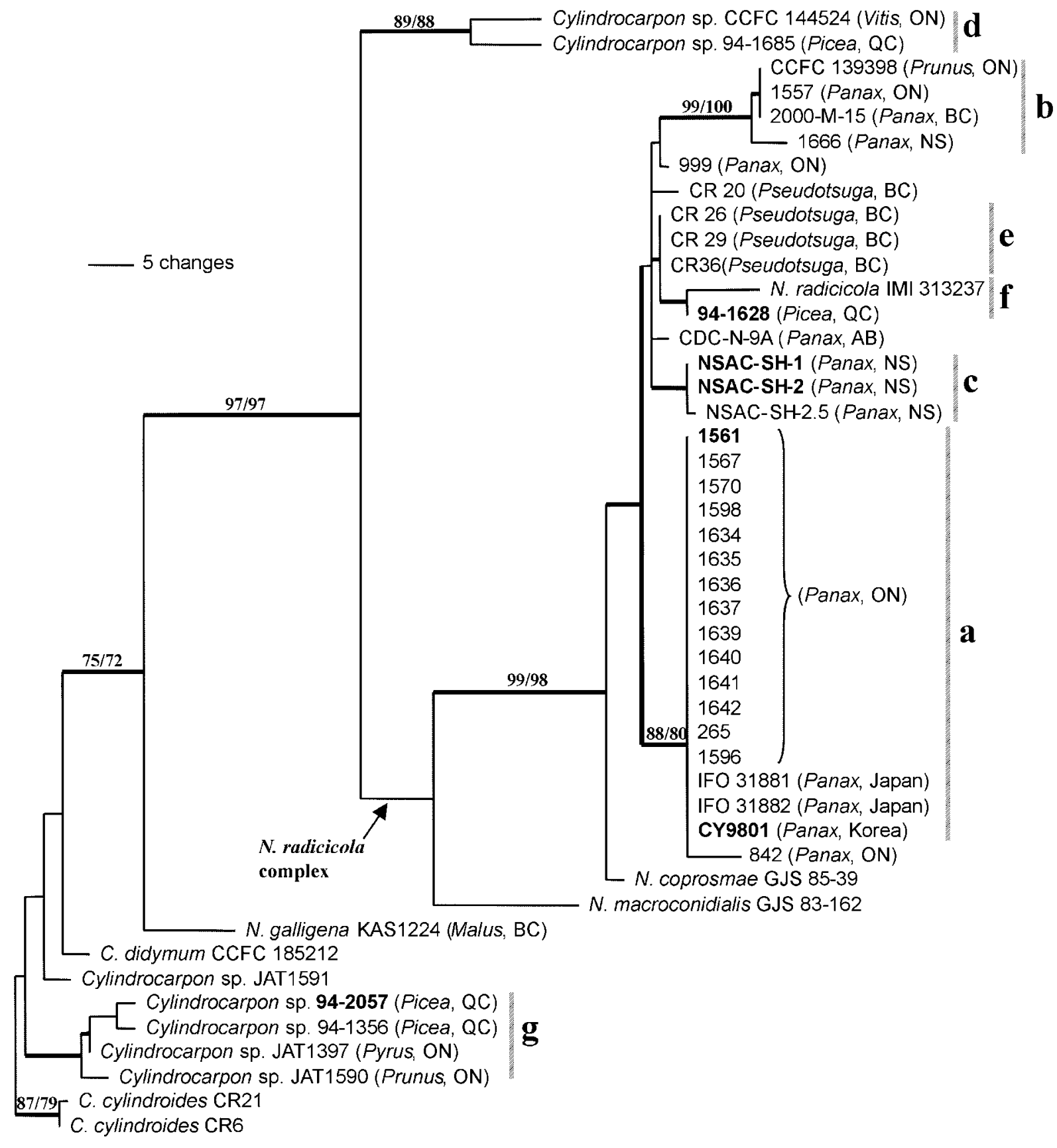

Fig. 3. Phylogenetic analysis of $\beta$-tubulin gene sequence data, including 37 sequences from strains of the Neonectria radicicola complex and 9 sequences from related species (GenBank Accession Nos. AY297172 to AY297217). Of 144 most parsimonious trees (MPTs) from a complete heuristic search, 1 is shown (96 characters, 205 steps, CI 0.629, RI 0.860, RC 0.541, HI 0.371). Branches occurring in 100\% of the MPTs (strict consensus) are in bold. The numbers above certain branches are bootstrap and jackknife values above $70 \%$. 
sets included had acceptable $P$ values; tests with any two of the sequences sets included were rejected. Therefore, we included the sequences of $N$. radicicola IMI 313237 in a combined analysis of 25 strains $(P=0.335)$, the results of which are shown in Figure 4. The combined $\beta$-tubulin-ITS analysis confirmed the phylogenetic structure derived from the $\beta$-tubulin and ITS analyses of the larger group of sequences. Strains from ginseng grouped in the same three well-defined clades noted above with the $\beta$-tubulin analysis, but with superior bootstrap and jackknife support. Apart from these well-defined clades, the phylogenetic structure for the remainder of the $N$. radicicola complex remained unresolved.

Molecular detection of highly aggressive ginseng isolates of C. destructans. A suppression-PCR genomic subtractive hybridization approach was taken to isolate DNA sequences from Ontario ginseng clade a isolate 1640 (19), which potentially could be used for the specific detection of the highly aggressive ginseng isolates of $C$. destructans represented in Figures 2 to 4 (clade a). A 1-kb subtraction product had some sequence similarity to nuclear ribosomal RNA gene IGS sequences of $F$. oxysporum isolates from
Douglas fir and Ponderosa pine (GenBank Accession Nos. U74329 and U74330, respectively), and hybridized to DNA from $F$. oxysporum, and all ginseng and other $C$. destructans isolates tested (19). However, there were sufficient differences between the $C$. destructans and $F$. oxysporum sequences to design PCR primers that potentially could be used to specifically amplify $C$. destructans DNA. Amplification with primer set CdU3/CdL1b produced an $\approx 500$-bp product from genomic DNA of the Korean and Ontario ( $\beta$-tubulin clade a) ginseng isolates of $C$. destructans (Table 3; Fig. 5A, lanes 4 to 13 and $B$, lanes 15 and 16), but not from ginseng isolates in other clades (Table 3; Fig. 5A, lanes 2 and 3, and data not shown), isolates of $C$. destructans from other hosts (Table 3), or isolates of other fungal species (Fig. 5B, lanes 1 to 14 ). DNA samples that did not yield an IGS amplicon could still be amplified with the Dest1/Dest4 primer set developed previously by Hamelin et al. for the detection of conifer isolates of $C$. destructans (12), or $\beta$-tubulin and ITS primer sets used to generate amplicons for sequence analysis (Table 3; Figs. 2 and 3, and data not shown), and, thus, were not refractory to amplification.

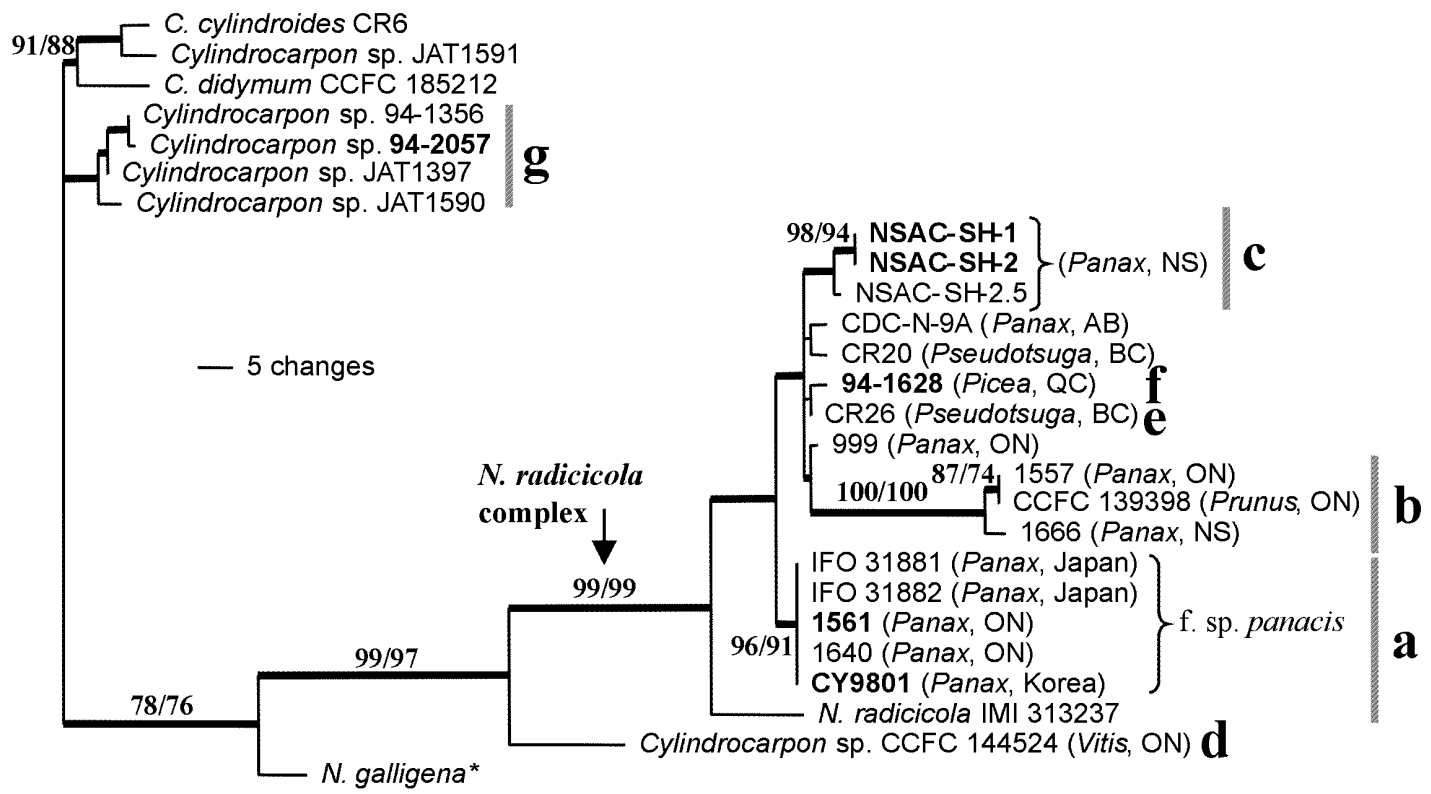

Fig. 4. Combined phylogenetic analysis of $\beta$-tubulin gene and rRNA gene internal transcribed spacer (ITS) sequences for 26 strains of Cylindrocarpon destructans and other Cylindrocarpon spp. (strains 94-1685, 94-2057, GJS-39, and GJS 83-162 were not included in this analysis). Of 118 most parsimonious trees (MPTs) from a complete heuristic search, 1 is shown (140 characters, 2,190 steps, CI 0.749, RI 0.901, RC 0.675, HI 0.251). Branches occurring in 100\% of the MPTs (strict consensus) are in bold. The numbers above certain branches are bootstrap and jackknife values above 70\%. Isolates used in pathogenicity tests are in bold type. The Neonectria galligena sequences (*) used in this data set include the ITS sequence from GenBank (Accession No. NGA228662) and the $\beta$-tubulin sequence from strain KAS 1224.

TABLE 3. Amplification of sequences from Cylindrocarpon destructans isolates

\begin{tabular}{|c|c|c|c|c|c|}
\hline \multirow[b]{2}{*}{ Isolate } & \multirow[b]{2}{*}{ Geographic origin } & \multirow[b]{2}{*}{ Host } & \multicolumn{3}{|c|}{ PCR amplification ${ }^{y}$} \\
\hline & & & Clade $^{z}$ & IGS & ITS \\
\hline 1640 & Ontario & Panax quinquefolius & $\mathrm{a}$ & + & + \\
\hline CY9802 & Korea & $P$. ginseng & $\mathrm{a}$ & + & + \\
\hline 1666 & Nova Scotia & P. quinquefolius & $\mathrm{b}$ & - & + \\
\hline CDC-N-9A & Alberta & P. quinquefolius & n.a. & - & + \\
\hline NSAC-SH-2.5 & Nova Scotia & P. quinquefolius & $\mathrm{c}$ & - & + \\
\hline CCFC 144524 & Ontario & Vitis vinifera & $\mathrm{d}$ & - & + \\
\hline CCFC 150670 & Alberta & Poa pratensis & n.a. & - & + \\
\hline $94-1628$ & Quebec & Picea glauca & $\mathrm{f}$ & - & + \\
\hline
\end{tabular}

y PCR, polymerase chain reaction; rRNA gene intergenic spacer (IGS) sequences were amplified with the CdU3/CdL1b primer set (this study); internal transcribed spacer (ITS) sequences were amplified with the Dest1/Dest4 primer set (12); presence or absence of a PCR amplicon is indicated by + or - , respectively.

${ }^{\mathrm{z}}$ Clade designations are according to Figures 2 and 3; isolates not assigned to a clade are indicated by n.a. 


\section{DISCUSSION}

One of the objectives of this work was to develop a DNA-based method to detect the aggressive ginseng strains of $C$. destructans. Thus, accurate genetic definition of these strains using complete ITS and partial $\beta$-tubulin sequences was a critical part of this work, but it quickly became clear that a high degree of genetic divergence exists among those strains isolated from ginseng and other hosts, and identified as C. destructans or Nectria radicicola. Given the comparative homogeneity of ITS sequences in the related species $N$. galligena, in which only a single transition was found in the ITS of one of 33 strains (14), this diversity was surprising, and suggested the existence of several phylogenetic species within the $N$. radicicola-C. destructans lineage. The occurrence of ginseng strains in several distinct clades, a similar dispersal of conifer derived strains, and the intermixing of strains from other hosts with ginseng and conifer isolates also suggest that host is not the driving force behind speciation in this complex. Similarly, there is no evident geographical structure to the data. More complete sampling of strains of this complex from other hosts will be necessary to completely resolve these species.

The high bootstrap value and long branch supporting $N$. radicicola var. macroconidialis in Figure 2, and the fact that the anamorph is already regarded as a distinct species (27), suggests that this variety should be raised to species rank. Similarly, $N$. radicicola var. coprosmae is basal to var. radicicola in both the ITS and $\beta$-tubulin trees, and was recognized as a distinct species when first described. Therefore, we propose the following nomenclature:

Neonectria coprosmae (Dingley) Seifert, comb. nov.

= Nectria coprosmae Dingley, Trans. Roy. Soc. N. Z. 79:200. 1951 (basionym).

= Nectria radicicola var. coprosmae (Dingley), Samuels \& Brayford, Mycol. Res. 94:438. 1990.

Anamorph: Cylindrocarpon coprosmae C. Booth, Mycol. Pap. 104:16. 1966.

Neonectria macroconidialis (Samuels \& Brayford) Seifert, stat. and comb. nov.

= Nectria radicicola var. macroconidialis Samuels \& Brayford, Mycol. Res. 94:440. 1990 (basionym).

Anamorph: Cylindrocarpon macroconidialis Brayford \& Samuels, Mycol. Res. 94:440. 1990.

In the ITS tree (Fig. 2), N. coprosmae and N. macroconidialis seem to be paraphyletic among the strains identified as $N$. radicicola, but this does not occur in the other analyses. The strains representing $N$. radicicola are still diverse; in fact, the ITS of the strain we sequenced (IMI 313237) is quite divergent from the other sequences obtained from GenBank. In the $\beta$-tubulin tree (Fig. 3), this strain is nested in the center of the main $N$. radicicola complex (Fig. 3, clades b to f) but, in the ITS and combined analyses, it is basal to this complex. The eventual discrimination of several segregate species seems inevitable if surveys concentrating on isolates from a broader range of hosts and geographical localities are undertaken.

The PCR primer set designed previously for the detection of $C$. destructans conifer isolates (12) was shown here to be useful for the detection of $C$. destructans in the broad sense from ginseng, including representative isolates from clades a, b, and c (Figs. 2 to 4 ), and also to detect nonconifer isolates in other Cylindrocarpon clades, including some that lie outside the main $N$. radicicola complex. Although members of clade a, including those isolates shown to cause severe root rot of ginseng, could not be differentiated from other strains by this diagnostic method, the primer set $\mathrm{Cdu} 3 / \mathrm{CdL} 1 \mathrm{~b}$, designed in this study, is useful for the specific detection of those isolates (Table 3; Fig. 5). To that end, this primer set currently is being used for the detection and quantitative assessment of these strains in Ontario soils and in plant tissue
(24). These data further emphasize that the design of speciesspecific PCR primers requires the development of accurate species concepts. This point is of particular importance when the ITS sequence is used as a source of primers, because different species within many groups of fungi may have identical ITS sequences (e.g., Fusarium [22] and Penicillium [29]).

Among the ginseng isolates analyzed, those from Korea and most from Ontario had identical ITS and $\beta$-tubulin sequences (Figs. 3 and 4, clade a), which differed from those of Ontario isolates 1557 (Figs. 3 and 4, clade b) and 999, collected in 1930 and 1992, respectively, and isolates collected in Alberta and Nova Scotia (Fig. 3, clade c). Because these isolates were not obtained at random from the different growing areas, but were supplied by cooperators or isolated from diseased roots supplied by cooperators, the genetic variation detected may not accurately reflect regional differences, but may simply reflect variation within the C. destructans complex.

With the exception of isolate 999, all of the Ontario ginseng isolates were obtained from either 3- or 4-year-old roots having symptoms of "disappearing root rot" $(13,35)$, or from severelydiseased seedlings grown in soils previously cropped to ginseng (25). The Korean isolates similarly were obtained from severely rotted roots. In the pathogenicity trials, ginseng isolates 1561 and 1640 from Ontario and CY9207 and CY9801 from Korea were very aggressive on ginseng (Table 2; Fig. 1; data not shown). In contrast, the ginseng isolates from Nova Scotia (NSAC-SH-1 and NSAC-SH-2), which formed a distinct main clade in the $N$. radicicola complex (Figs. 3 and 4), had significantly lower dis-
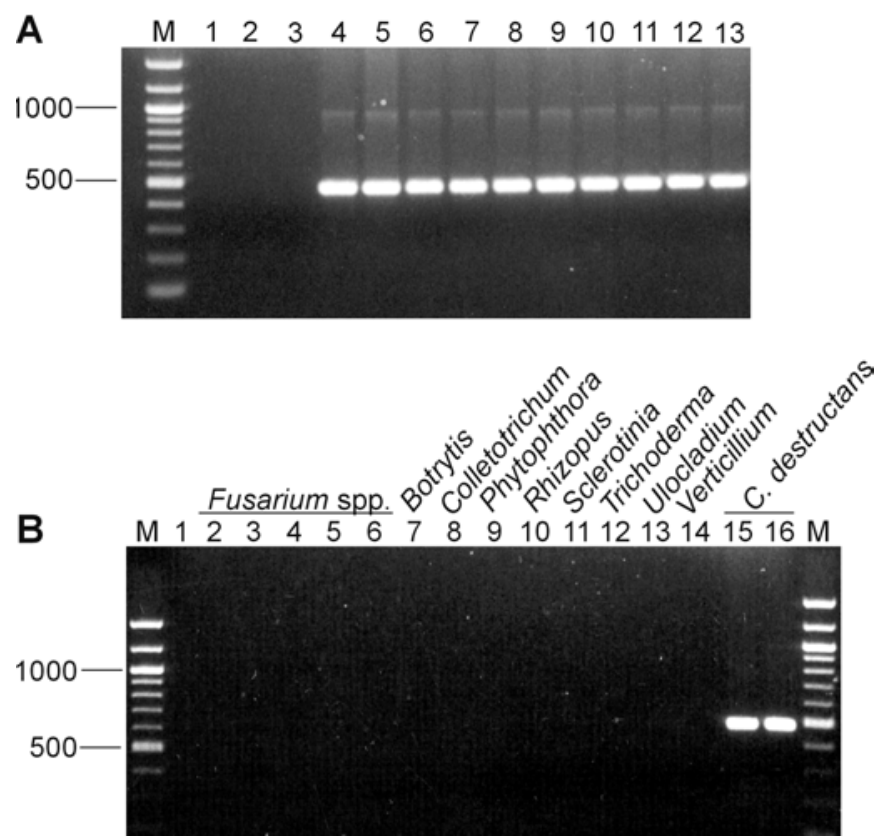

Fig. 5. Polymerase chain reaction (PCR) amplification with primer set CdU3/CdL1b of genomic DNA sequences from Cylindrocarpon destructans and other fungal species. Amplifications were carried out as described in Materials and Methods. PCR products were separated on 1\% agarose gels and stained with ethidium bromide. Molecular size standards (100-bp ladder) (New England Biolabs) are shown in lane $\mathrm{M}$ of each panel. A, Isolates of $C$. destructans from ginseng: lane 1, sterile distilled water; lanes 2 and 3, Ontario clade b isolates 1557 and 1666; lanes 4 to 11, Ontario clade a isolates 265, 842, 1287, 1567, 1596, 1636, 1637, and 1640; lanes 12 and 13, Korean isolates CY9801 (clade a) and CY9802. B, Lane 1, sterile distilled water; lanes 2 to 4, Fusarium oxysporum isolates 1704, 1706, and 1833; lanes 5 to 6, F. solani isolates 1121 and 1124; lane 7, Botrytis cinerea isolate 1951; lane 8, Colletotrichum coccodes isolate 1812; lane 9, Phytophthora sojae; lane 10, Rhizopus arrhizus; lane 11, Sclerotinia sclerotiorum; lane 12, Trichoderma viridae; lane 13, Ulocladium atrum; lane 14, Verticillium dahliae isolate Dvd-T5; lanes 15 and 16, Cylindrocarpon destructans ginseng isolates CY9802 (Korea) and 1640 (Ontario, clade a). 
ease indices and caused no significant stand loss, being comparable in pathogenicity to two conifer strains representing different clades. These less aggressive strains of $C$. destructans, and perhaps other Cylindrocarpon spp., may be associated with the "rusted root" disease of ginseng $(4,13,35)$.

The similarity in DNA characters and pathogenicity of the Korean $P$. ginseng isolates to those of isolates from $P$. quinquefolius grown in Ontario was unexpected, because cultivation of $P$. quinquefolius currently is rare in Korea, and $P$. ginseng is seldom grown in North America (23). One possible explanation is that the two ginseng species have at some time during the past two centuries been grown in close proximity, as a result of trade-based movement of Panax germ plasm between Asia and North America, thus allowing the development of aggressive strains adapted to both species. Alternatively, a common vector species that is widely distributed also might be responsible for the dispersal of similar strains.

Our data demonstrate that the majority of isolates from contemporary Ontario ginseng cultivation share identical $\beta$-tubulin gene and rRNA gene ITS sequences with strains identified as $C$. destructans f. sp. panacis by Matuo and Miyazawa (18), the cause of a devastating root rot of $P$. ginseng in parts of Japan. Matuo and Miyazawa initially described their fungus as a new species, $C$. panacis (17). However, according to the International Code of Botanical Nomenclature, C. panacis is an invalid species name because no type specimen was designated (Art. 37.1). The informal rank of forma specialis, widely used in plant pathology, especially for host-specific strains, thus seems an appropriate designation for these aggressive strains.

\section{ACKNOWLEDGMENTS}

This study was supported in part by the Ontario Research Enhancement Program; some sequencing was undertaken for a separate project supported by the Canadian Biotechnology Strategy. We thank P. Axelrood, K. F. Chang, R. Hamelin, S. Hong, K. Nakagiri (IFO), G. J. Samuels, J. Traquair, Y.-H. Yu, and the Canadian Collection of Fungal Cultures for providing Cylindrocarpon isolates; M. Dumas (Great Lakes Forestry Centre, Sault Ste. Marie, ON) for providing seed of Picea glauca; $\mathrm{G}$. Louis-Seize for completing some of the $\beta$-tubulin gene sequencing; S. Grant, L. Tomlinson, and B. Capell for technical assistance; I. van Grinsven and S. Millar for sequencing carried out at the SCPFRC, and K. O'Donnell (USDA-ARS, Peoria, IL) for advice on the partition homogeneity test.

\section{LITERATURE CITED}

1. Akopyants, N. S., Fradkov, A., Diatchenko, L., Hill, J. E., Siebert, P. D., Lukyanov, S. A., Sverdlov, E. D., and Berg, D. E. 1998. PCR-based subtractive hybridization and differences in gene content among strains of Helicobacter pylori. Proc. Natl. Acad. Sci. USA 95:13108-13113.

2. Bennett, J. W., and Lasure, L. L. 1991. Growth media. Page 470 in: More Gene Manipulations in Fungi. J. W. Bennett and L. L. Lasure, eds. Academic Press, San Diego, CA.

3. Booth, C. D. 1966. The genus Cylindrocarpon. Mycol. Pap. (CMI) 104:1-56.

4. Brammall, R. A. 1994. Ginseng. Pages 294-299 in: Diseases and Pests of Vegetable Crops in Canada. R. J. Howard, A. J. Garland, and W. L. Seaman, eds. Phytopathological Society and Entomological Society of Canada, Ottawa, Ontario, Canada.

5. Brown, A. E., Muthumeenakshi, S., Sreenivasaprasad, S., Mills, P. R., and Swinburne, T. R. 1993. A PCR primer-specific to Cylindrocarpon heteronema for detection of the pathogen in apple wood. FEMS Microbiol. Lett. 108:117-120.

6. Diatchenko, L., Lau, Y. F. C., Campbell, A. P., Chenchik, A., Moqadam, F., Huang, B., Lukyanov, S., Lukyanov, K., Gurskaya, N., Sverdlov, E. D., and Siebert, P. D. 1996. Suppression subtractive hybridization: A method for generating differentially regulated or tissue-specific cDNA probes and libraries. Proc. Natl. Acad. Sci. USA 93:6025-6030.
7. Dobinson, K. F. 1995. Genetic transformation of the vascular wilt fungus Verticillium dahliae. Can. J. Bot. 73:710-715.

8. Dobinson, K. F., Harris, R. E., and Hamer, J. E. 1993. Grasshopper, a long terminal repeat (LTR) retroelement in the phytopathogenic fungus Magnaporthe grisea. Mol. Plant-Microbe Interact. 6:114-126.

9. Dobinson, K. F., Tenuta, G. K., and Lazarovits, G. 1996. Occurrence of race 2 of Verticillium dahliae in processing tomato fields in southwestern Ontario. Can. J. Plant Pathol. 18:55-58.

10. Edwards, K., Johnstone, C., and Thompson, C. 1991. A simple and rapid method for the preparation of plant genomic DNA for PCR analysis. Nucleic Acids Res. 19:1349.

11. Gardes, M., and Bruns, T. D. 1993. ITS primers with enhanced specificity for basidiomycetes - application to the identification of mycorrhizae and rusts. Mol. Ecol. 2:113-118.

12. Hamelin, R. C., Berube, P., Gignac, M., and Bourassa, M. 1996. Identification of root rot fungi in nursery seedlings by nested multiplex PCR. Appl. Environ. Microbiol. 62:4026-4031.

13. Hildebrand, A. A. 1935. Root rot of ginseng in Ontario caused by members of the genus Ramularia. Can. J. Res. 12:82-114.

14. Langrell, S. R. H. 2002. Molecular detection of Neonectria galligena (syn. Nectria galligena). Mycol. Res. 106:280-292.

15. Little, T. M., and Hills, F. J. 1978. Agricultural Experimentation-Design and Analysis. John Wiley and Sons, Toronto.

16. Mantiri, F., Samuels, G. J., Rahe, J. E., and Honda, B. M. 2001. Phylogenetic relationships in Neonectria species having Cylindrocarpon anamorphs inferred from mitochondrial ribosomal DNA sequences. Can. J. Bot. 79:334-340.

17. Matuo, T., and Miyazawa, Y. 1969. Cylindrocarpon panacis sp. nov. causing root rot of ginseng. Trans. Mycol. Soc. Jpn. 9:109-112.

18. Matuo, T., and Miyazawa, Y. 1984. Scientific name of Cylindrocarpon sp. causing root rot of ginseng. Ann. Phytopathol. Soc. Jpn. 50:649-652.

19. McMullen, C. R. 2000. Genetic diversity and molecular detection of the fungus Cylindrocarpon destructans. M.Sc. thesis, University of Western Ontario, London, Ontario, Canada.

20. Miller, J. D., Greenhalgh, R., Wang, Y. Z., and Lu, M. 1991. Tricothecene chemotypes of three Fusarium species. Mycologia 83:121-130.

21. O'Donnell, K., and Cigelnik, E. 1997. Two divergent intragenomic rDNA ITS2 types within a monophyletic lineage of the fungus Fusarium are nonorthologous. Mol. Phylogenet. Evol. 7:103-116.

22. O'Donnell, K., Cigelnik, E., and Nirenberg, H. I. 1998. Molecular systematics and phylogeography of the Gibberella fujikuroi species complex. Mycologia 90:465-493.

23. Proctor, J. T. A., and Bailey, W. G. 1987. Ginseng: Industry, botany and culture. Hortic. Rev. 9:187-236.

24. Reeleder, R. D., Capell, B. B., Tomlinson, L. D., and Hickey, W. J. 2003. The extraction of fungal DNA from multiple large soil samples. Can. J. Plant Pathol. 25:182-191.

25. Reeleder, R. D., Roy, R., and Capell, B. 2002. Seed and root rots of ginseng (Panax quinquefolius L) caused by Cylindrocarpon destructans and Fusarium spp. J. Ginseng Res. 26:151-158.

26. Rossman, A. Y., Samuels, G. J., Rogerson, C. T., and Lowen, R. 1999. Genera of Bionectriaceae, Hypocreaceae and Nectriaceae (Hypocreales, Ascomycetes). Stud. Mycol. 42:1-248.

27. Samuels, G. J., and Brayford, D. 1990. Variation in Nectria radicicola and its anamorph, Cylindrocarpon destructans. Mycol. Res. 94:433-442.

28. Seifert, K. A., and Axelrood, P. E. 1998. Cylindrocarpon destructans var. destructans. Can. J. Plant Pathol. 20:115-117.

29. Skouboe, P., Frisvad, J. C., Taylor, J. W., Lauritsen, D., Boysen, M., and Rossen, L. 1999. Phylogenetic analysis of nucleotide sequences from the ITS region of terverticillate Penicillium species. Mycol. Res. 103:873-881.

30. Swofford, D. 1999. PAUP*: Phylogenetic analysis using parsimony (*and other methods A), version 4.0b4a. Sinauer Associates, Sunderland, MA.

31. Tautz, D., and Renz, M. 1983. An optimized freeze-squeeze method for the recovery of DNA fragments from agarose gels. Anal. Biochem. 132:14-19.

32. Traquair, J. A., and White, G. P. 1992. Cylindrocarpon rot of fruit trees in cold storage. Can. J. Plant Pathol. 14:310-314.

33. White, T. J., Bruns, T., Lee, S., and Taylor, J. 1990. Amplification and direct sequencing of fungal ribosomal RNA genes for phylogenetics. Pages 249-258 in: PCR Protocols: A Guide to Methods and Applications. M. A. Innis, D. H. Gelfand, J. J. Sninsky, and T. J. White, eds. Academic Press, San Diego, CA.

34. Zhou, T., and Reeleder, R. D. 1989. Application of Epicoccum purpurascens spores to control white mold of bean. Plant Dis. 73:639-642.

35. Zinnsmeister, C. L. 1918. Ramularia root-rots of ginseng. Phytopathology 8:557-571. 